\title{
Drought, deer mice, and a new disease in Death Canyon
}

For six years - drought. Then in the spring of 1993 in the Four Corners area of New Mexico, Arizona, Colorado, and Utah, including Muerto Canyon, New Mexico, there was heavy rain and snow. The conditions were good for the deer mice because there was an abundance of pine nuts and grasshoppers, which they eat, and a dearth of foxes, snakes, and owls, which eat them.

In May 1993 people, mainly American Indians, began to die of an acute illness characterised by prodomal fever followed by severe respiratory distress and shock. Within a matter of a few weeks the disease was shown to be due to a new species of hantavirus. ${ }^{\star}$ The disease has been called hantavirus pulmonary syndrome and the virus, Muerto Canyon virus. The first two cases were notified on 14 May. By 7 June there were 24 cases, 12 of whom died. Since then the disease has spread to 14 western states and the total number of cases has risen to more than $\mathbf{5 0 .}$ Isolated cases have been reported in eastern states.

A paper in the New England fournal of Medicine (Jeffrey S Duchin and colleagues, 1994; 330: 949-55) gives details of the first 17 cases shown to be infected with hantavirus on the basis of serum antibody tests, testing of lung tissue for hantavirus using the polymerase chain reaction, or immunohistochemical staining of fixed tissues. The patients were between 13 and 64 years old and $13(76 \%)$ were American Indian. There was a $76 \%$ mortality. They were admitted to hospital, on average, five days after the onset of a prodomal illness the prominent features of which were fever, myalgia, cough, headache, nausea, and vomiting. Some patients had diarrhoea. When first examined in hospital all 17 patients were tachypnoeic and most were feverish and had a tachycardia. Half of them were hypotensive and one third had crackles or râles on auscultation of the chest. Several patients had abdominal tenderness. Common findings on investigation included proteinuria, neutrophil leucocytosis, often with myeloid precursors, atypical mononuclear cells, thrombocytopenia, prolonged prothrombin and partial thromboplastin times, and raised serum lactate dehydrogenase concentration. Those who did badly developed progressive pulmonary oedema, hypoxia, and hypotension soon after admission. In the 13 fatal cases the mean duration between onset of symptoms and death was 8 days (range $2-16$ days).

At postmortem examination there were large serous pleural effusions and severe lung oedema. Histology of the lungs showed oedema in the alveoli with some hyaline membranes and interstitial lymphocytic infiltration but no viral inclusions or cytopathic effect. Extrapulmonary findings were limited to infiltration with atypical mononuclear cells in liver and spleen. The pulmonary oedema is thought to be due to increased capillary permeability.

At the same time as this epidemic a tenfold increase in the deer mice population in the Four Corners region was documented. Thirty per cent of the deer mice tested were seropositive for hantavirus.

The story contains both a warning and reason for satisfaction. The warning, that new infectious diseases will continue to appear; the satisfaction, that the cause was discovered so quickly.

*Hantaviruses belong to the family Bunyaviridae and are named after the Hantaan river in South Korea where the first hantavirus was discovered. In the Korean war of the 1950s many troops had Korean haemorrhagic fever and hantaviruses have caused 'haemorrhagic fever and renal syndrome' in Asia and eastern Europe. Severe lung pathology has not been a common feature of hantavirus disease in the past and usually the illnesses have been relatively mild. 